\title{
A Cross-Sectional Survey of the Prevalence and Determinants of Overweight and Obesity Among Primary Healthcare Professional Nurses In Eastern Cape, South Africa
}

\author{
Sizeka Monakali ${ }^{1}$, Daniel Ter Goon ${ }^{1}$, Eunice Seekoe ${ }^{1} \&$ Eyitayo Omolara Owolabi ${ }^{1}$ \\ ${ }^{1}$ Department of Nursing Science, Faculty of Health Sciences, University of Fort Hare, East London, South Africa \\ Correspondence: Eyitayo Omolara Owolabi Department of Nursing Science, Faculty of Health Sciences, \\ University of Fort Hare, East London, 5200 South Africa. Tel: 27-73-071-9622. E-mail: \\ owolabiomolara101@gmail.com
}

Received: August 17, 2018 Accepted: October 18, 2018 Online Published: March 15, 2019

doi:10.5539/gjhs.v11n4p53 URL: https://doi.org/10.5539/gjhs.v11n4p53

\begin{abstract}
There is a paucity of data on the burden of obesity among primary Health care professional nurses in Eastern Cape Province of South Africa. This study examines the prevalence and determinants of overweight and obesity among Primary Healthcare Professional nurses in Eastern Cape Province of South Africa. This workplace cross-sectional study was conducted among 203 Primary Health Care Professional nurses selected conveniently across 41 primary healthcare facilities in Eastern Cape, South Africa following a the WHO STEPwise approach and using the WHO STEPwise questionnaire for data collection. Data were expressed as mean, counts and proportions, as appropriate. We compared percentages using chi-square test. Descriptive and inferential statistics were conducted. Seventy six percent of the nurses were obese and $18 \%$ were overweight. Age, gender, marital status, duration of practice, alcohol use and smoking were significantly associated with obesity. Only age $>30$ years and not using alcohol were independent predictors of obesity, after adjusting for confounders. We found a high prevalence of obesity among primary healthcare professional nurses in this setting. This constitute future risk for an increased prevalence of chronic diseases among the healthcare workforce in this setting. There is a need for measures to promote healthy lifestyle behaviours and weight management among nurses in this setting.
\end{abstract}

Keywords: obesity, professional nurses, primary healthcare, health promotion, Eastern Cape, South Africa

\section{Introduction}

Overweight and obesity are key public health challenges, and form part of the leading risk factors for chronic diseases, morbidity and mortality worldwide (WHO, 2016). Currently, over 1.9 billion adults are overweight and over half a billion are obese (Finucane et al., 2011; WHO, 2016) with an inevitable increase in the nearest future if actions are not taken. No doubt, overweight and obesity are grossly preventable as they are largely driven by unhealthy lifestyle behaviours involving dietary practices and physical inactivity (Nnyepia, Gwisai, Lekgoa, \& Seru, 2015; WHO, 2014). However, genetics, socio-economic status, ethnicity, food marketing and physical environment impact greatly on these modifiable factors which often makes the prevention of obesity a challenging task (Aryee, Helegbe, Baah, Sarfo-Asante, \& Quesit-Therson, 2014).

The pledge of a long and healthy life by the South African government for all its citizens is threatened by the grievous burden of overweight and obesity. Healthy lifestyle education and advocacy is important for the reduction of overweight and obesity (Steyn et al., 2004). Given this, health professionals can be outlined as essential stakeholders in fostering the reduction of obesity burden and the achievement of the pledged healthy life for all South Africans. Nurses in particular, who constitute the larger proportion of the healthcare workforce (Aryee et al., 2013; Ogunjimi, Ikorok, \& Olayinka, 2010) have major roles to play in health education and health promotion activities towards weight management.

Several studies conducted on obesity among nurses across different countries; South Africa (Goon et al., 2013), Nigeria (Ogunjimi, Ikorok, \& Olayinka, 2010), Scotland (Kyle, Neall, \& Artherton, 2016), United Kingdom, Australia and New Zealand (Bogossian et al., 2012) documented a high prevalence of obesity among nurses. Factors such as unhealthy lifestyle, dietary practices (Phiri, Draper, Lambert, \& Kolbe-Alexander, 2014), work-related stress, burnout (Khamisa, Peltzer, \& Olderburg, 2013), and physical inactivity (Goon et al., 2013) ${ }^{8}$ have been reported to be associated with obesity among nurses. Technological advancement which has brought 
about the use of several equipment in healthcare, with limited energy expenditure have also being advanced as another contributing factor to physical inactivity and consequently, obesity among nurses (Ogunjimi et al., 2010). Overweight and obesity among nurses is deleterious both to the nurses and the healthcare workforce at large. Apart from the fact that obesity among nurses predispose them to chronic illnesses, it also renders them less active at work (Ogunjimi et al., 2010) and might paralyse the healthcare system if the supposed caregivers eventually become care receivers. Also, overweight and obese nurses have been shown to have less confidence in health educating their patients on weight management (Kyle, Neall, \& Atherton, 2016).

Primary healthcare professional nurses are patients' first point of contact to the healthcare system and in most cases independent health decision makers (South African Nursing Council [SANC], 2005). Likewise, health education on health promotion activities for weight management forms part of the core activities conducted at this level of healthcare (SANC, 2005). Thus, this group are an important healthcare group, yet, a high risk group for physical inactivity and obesity as a result of the nature of their work which entails hours of sitting during consultations. However, majority of the studies on obesity among healthcare professionals are majorly conducted at either the secondary or tertiary level of care (Aryee et al., 2013; Goon et al., 2013; Kyle, Neall, \& Artherton, 2016; Ogunjimi et al., 2010; Skaal \& Pengpid, 2014), neglecting the primary healthcare givers. The prevalence of overweight and obesity reported in these studies ranged from $43.3 \%$ among Ghanaian nurses (Aryee et al., 2013) to as high as $79.1 \%$ among nurses in South Africa (Goon et al., 2013). Overweight and obesity is not just peculiar to nurses, Skaal and Pengpid (2011) documented a high prevalence of overweight and obesity among healthcare workers in general, however, nurses were found to have the highest prevalence of overweight and obesity. The study conducted by Kyle et al. (2017) among England workers also showed a higher odds for obesity among nurses. Given the paucity of data on this burden among primary healthcare nurses, especially in this setting, this study therefore examines the prevalence and determinants of overweight and general obesity among professional primary healthcare nurses in the Eastern Cape Province of South Africa. This information could assist in assessing the potential of the primary healthcare nurses as role models of healthy lifestyle and as well help in formulating weight management guidelines and policies tailored to professional nurses.

\section{Methodology}

\subsection{Study Area and Design}

This study utilised a quantitative, descriptive and cross-sectional approach to screen for the prevalence of overweight and obesity among professional primary health care nurses, working across 41 primary healthcare (PHC) facilities in Eastern Cape. The Eastern Cape as one of the province in South Africa has its capital in Bisho. The province came into being in 1994, originating from the Xhosa homes in Transkei and Ciskei in addition to the eastern part of the then Cape Province. Eastern Cape province comprises of two metropolitan municipalities namely; Metropolitan Municipality (BCMM), Nelson Mandela Metropolitan Municipality as well as six districts; Amathole, Joe Gqabi, O.R Tambo, Sarah Bartman, Chris Hani and Alfred Ndzo.

\subsection{Sampling}

This study utilized a purposive sampling to select primary health care nurses from four randomly selected districts. We randomly selected four of the eight metropoles/districts in the province following a simple randomization technique. The selected four districts are; Buffalo City Metropolitan Municipality, O.R Tambo, Chris Hani, and Sarah Baartman Districts. We assigned numbers to the eight districts and concealed the numbers. Afterwards, four of them were blindly and randomly selected. Out of these selected districts/municipalities, we conveniently selected 41 primary healthcare facilities.

Based on the statistics gathered from the provincial Department of Health, the total number of nurses in the four selected districts are $880(\mathrm{OR}$ Tambo $=250$, Chris Hani $=230$, Sarah Baartman $=100$, and BCMM=300). For representativeness, at a confidence level of $95 \%$ and confidence interval of \pm 5 , the required sample size was 268 nurses. However, only 203 primary health professional nurses (PNs), that is $76 \%$ of the required number of nurses, were accessible and included in the study due to shortage of staff in PHC facilities, especially in rural districts like OR Tambo. The study was conducted between February and May, 2017.

\subsection{Eligibility Criteria}

Primary healthcare professional nurses, aged 18 years and above, practicing in the PHC facilities, on duty and willing to participate in the study during the day of data collection were considered eligible for the study. Exclusion criteria were pregnancy or any form of debilitation in such a manner that obtaining anthropometric measures was difficult. 


\subsection{Data Collection Instrument}

The modified WHO STEPwise questionnaire (Bonita et al., 2003) which comprises of three major sections; demographic data, behavioral data and anthropometric measurements was used for data collection. In order to determine suitability of the instrument, a pilot study was conducted among $20 \mathrm{PHC}$ professional nurses at Mnquma sub district in Amathole district of the province.

\subsection{Ethical Consideration}

The ethical clearance was obtained from the Research and Ethics Committee of the University of Hare (Reference number; EC-2015RP10-426) which followed the Helsinki Declaration. Permission to conduct the study was requested from the Eastern Cape Department of Health $(\mathrm{ECDoH})$, district managers, sub district managers and facility managers. All participants provided written informed consent to participate in this study. Anonymity and confidentiality were ensured.

\subsection{Data Collection}

We used face-to-face interview to obtain information on demographic and behavioural characteristics. We also measured anthropometric indices and blood pressure. Demographic variables included items on sex, age, marital status, level of education, employment status, duration of practice and average monthly income. The following behavioural variables were obtained by self-reporting; smoking, alcohol use (assessed by self-reporting on use for the past 30 days) and physical activity (obtained by self-reported engagement in moderate to vigorous and intensity exercises using yes/no).

\subsection{Measurements}

Anthropometric measurements followed the standard anthropometric methods of the International Society for the Advancement of Kinanthropometry (ISAK) (Marfell-Jones, Olds, \& Stew, 2011). Body weight was measured in light clothes to the nearest $0.01 \mathrm{~kg}$ in the standing position using a SECA Scale (SECA Co., North America). Height was measured to the nearest $0.1 \mathrm{~m}$ by stadiometer in standing position with closed feet, without shoes. Overweight was defined as a body mass index (BMI) of $25-29.9 \mathrm{~kg} / \mathrm{m}^{2}$, and obesity was defined as a BMI of $\geq 30$ $\mathrm{kg} / \mathrm{m}^{2}$ (WHO, 2016). All measurements were taken by a professional nurse who was further trained on obtaining anthropometric measurements to ensure uniformity. The same set of equipment was used for all the study participants.

\subsection{Data Analysis}

Data were analysed using SPSS version 23 for windows (SPSS Inc., Chicago, IL, USA). Data were expressed as mean values \pm standard deviations $(\mathrm{SD})$ for continuous variables. Counts (frequency $=\mathrm{n}$ ) and proportions $(\%)$ were reported for categorical variables. Percentages were compared using chi-square test. We used descriptive and inferential statistics to determine the prevalence and determinants of overweight and obesity among the study participants. All the variables which were significantly associated in the bivariate analysis were put in the logistic regression model analysis. An unadjusted regression analysis was done by computing models for each of the independent variables while the adjusted regression analysis included a model containing all the independent variables which was then adjusted for confounder, smoking. A p-value of $<0.05$ was considered statistically significant.

\section{Results}

Table 1 presents socio demographic characteristics of the participants. The analysis included 203 participants. The mean age of the study participants was $45.17(\mathrm{SD} \pm 11.26)$ years while the average duration of practice was 15.98 $(\mathrm{SD} \pm 11.07)$ years. About half of the participants were married (49.8\%), single (40.9\%), have a diploma certificate in nursing (65\%) and earning more than 1,135 USD (60.6\%).

The mean self-reported hours of sitting at work was $4.4(\mathrm{SD} \pm 1.5)$ hours. 
Table 1. Socio-demographic characteristics of participants by gender

\begin{tabular}{|c|c|c|c|}
\hline Variable & All & Female & Male \\
\hline \multicolumn{4}{|l|}{ Age } \\
\hline 21 to 30 years & $26(12.8)$ & $19(10.6)$ & $7(29.2)$ \\
\hline 31 to 40 years & $50(24.6)$ & $41(22.9)$ & $9(37.5)$ \\
\hline 41 to 50 years & $42(20.7)$ & $39(21.8)$ & $3(12.5)$ \\
\hline 51 to 60 years & $74(36.5)$ & $69(38.5)$ & $5(20.8)$ \\
\hline 61 to 70 years & $11(5.4)$ & $11(6.1)$ & $0(0.0)$ \\
\hline \multicolumn{4}{|l|}{ Marital Status } \\
\hline Single & $83(40.9)$ & $71(39.7)$ & $12(50.0)$ \\
\hline Married & $101(49.8)$ & $90(50.3)$ & $11(45.8)$ \\
\hline Divorced & $9(4.4)$ & $9(5.0)$ & $0(0.0)$ \\
\hline Separated & $1(0.5)$ & $1(0.6)$ & $0(0.0)$ \\
\hline Widow/Widower & $9(4.4)$ & $8(4.5)$ & $1(4.2)$ \\
\hline \multicolumn{4}{|l|}{ Number of Children } \\
\hline 1 & $37(20.4)$ & $33(20.4)$ & $4(21.1)$ \\
\hline 2 & $61(33.7)$ & $58(35.8)$ & $3(15.8)$ \\
\hline 3 & $58(32.0)$ & $49(30.2)$ & $9(47.4)$ \\
\hline 4 & $18(9.9)$ & $16(9.9)$ & $2(10.5)$ \\
\hline 5 & $5(2.8)$ & $5(3.1)$ & $0(0.0)$ \\
\hline 6 & $1(0.6)$ & $1(0.6)$ & $0(0.0)$ \\
\hline 7 & $1(0.6)$ & $0(0.0)$ & $1(5.3)$ \\
\hline \multicolumn{4}{|l|}{ Level of Education } \\
\hline Diploma & $132(65.0)$ & $117(65.4)$ & $15(62.5)$ \\
\hline Degree & $67(33.0)$ & $58(32.4)$ & $9(37.5)$ \\
\hline Post-graduate Diploma & $3(1.5)$ & $3(1.7)$ & $0(0.0)$ \\
\hline Masters & $1(0.5)$ & $1(0.6)$ & $0(0.0)$ \\
\hline \multicolumn{4}{|l|}{ Race } \\
\hline Black & $195(96.1)$ & $171(95.5)$ & $24(100.0)$ \\
\hline Coloured & $8(3.9)$ & $8(4.5)$ & $0(0.0)$ \\
\hline \multicolumn{4}{|l|}{ Duration of Practice } \\
\hline 1 to 10 years & $72(40.7)$ & $59(38.1)$ & 13(59.1) \\
\hline 11 to 20 years & $41(23.2)$ & $37(23.9)$ & $4(18.2)$ \\
\hline 21 to 30 years & $44(24.9)$ & $41(26.5)$ & $3(13.6)$ \\
\hline 31 and above & $20(11.3)$ & $18(11.6)$ & $2(9.1)$ \\
\hline \multicolumn{4}{|l|}{ Income (USD) } \\
\hline $755-1135$ & $65(39.4)$ & $55(38.5)$ & $10(45.5)$ \\
\hline Above 1135 & $100(60.6)$ & $88(61.5)$ & $12(54.5)$ \\
\hline
\end{tabular}

Eighteen percent of the participants were overweight. The prevalence of obesity among the study participants was $76 \% ; 29 \%$ for obesity grade III, $24 \%$ for obesity grade I and $23 \%$ for obesity grade II (Figure 1). 


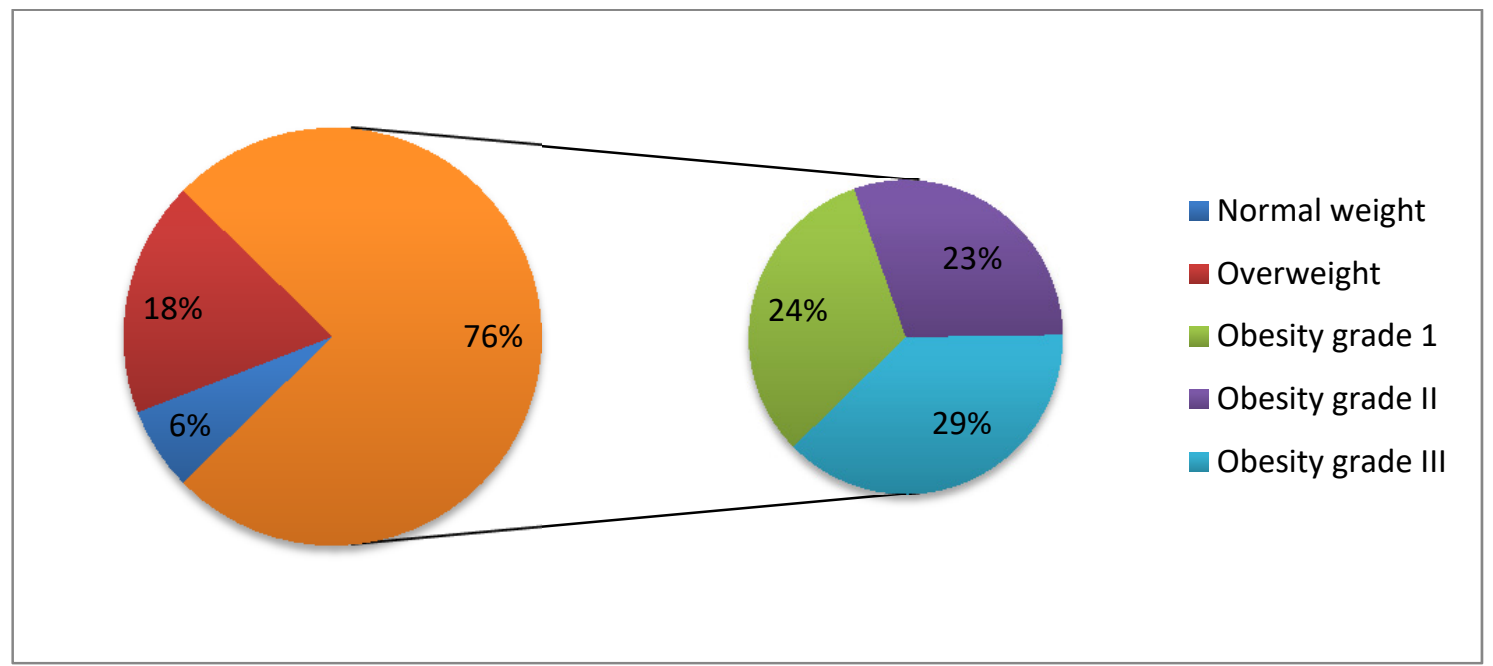

Figure 1. Prevalence of obesity

Obesity was significantly associated with gender, marital status, age, duration of practice, alcohol use and smoking among the study participants (Table 2).

Table 2. Association between obesity, demographic and behavioural variables

\begin{tabular}{|c|c|c|c|c|}
\hline Variable & All n(\%) & Obese n(\%) & Not Obese n(\%) & p-value \\
\hline \multicolumn{5}{|l|}{ Gender } \\
\hline Male & $24(11.8)$ & $11(45.8 \%)$ & $13(54.2)$ & 0.001 \\
\hline Female & $179(88.2)$ & $142(79.3)$ & $37(20.7)$ & \\
\hline \multicolumn{5}{|l|}{ Marital status } \\
\hline Single & $83(40.9)$ & $53(63.9)$ & $30(36.1)$ & 0.006 \\
\hline Married & 101(49.8) & $87(86.1)$ & $14(13.9)$ & \\
\hline Divorced & $9(4.4)$ & $5(55.6)$ & $4(44.4)$ & \\
\hline Separated & $1(0.5)$ & $1(100.0)$ & $0(0.0)$ & \\
\hline Widow/Widower & $9(4.4)$ & $7(77.8)$ & $2(22.2)$ & \\
\hline \multicolumn{5}{|l|}{ Number of Children } \\
\hline 1 & $37(20.4)$ & $29(78.4)$ & $8(21.6)$ & 0.501 \\
\hline More than 1 & 144(79.6) & $115(79.9)$ & $29(20.1)$ & \\
\hline \multicolumn{5}{|l|}{ Level of education } \\
\hline Diploma & $132(65.0)$ & $106(80.3)$ & $26(19.7)$ & 0.062 \\
\hline Degree & $67(33.0)$ & $45(67.2)$ & $22(32.8)$ & \\
\hline Post-graduate diploma & $3(1.5)$ & $2(66.7)$ & $1(33.3)$ & \\
\hline Masters & $1(0.5)$ & $0(0.0)$ & $1(100.0)$ & \\
\hline \multicolumn{5}{|l|}{ Race } \\
\hline Black & $195(96.1)$ & $147(75.4)$ & $48(24.6)$ & 0.628 \\
\hline Coloured & $8(3.9)$ & $6(75.0)$ & $2(25.0)$ & \\
\hline \multicolumn{5}{|l|}{ Age } \\
\hline 21 to 30 & $26(12.8)$ & $9(34.6)$ & $17(65.4)$ & $<0.001$ \\
\hline 31 to 40 & $0(24.6)$ & $37(74.0)$ & $13(26.0)$ & \\
\hline
\end{tabular}




\begin{tabular}{llll}
\hline 41 to 50 & $42(20.7)$ & $33(78.6)$ & $9(21.4)$ \\
51 to 60 & $74(36.5)$ & $65(87.8)$ & $9(12.2)$ \\
61 to 70 & $11(5.4)$ & $9(81.8)$ & $2(18.2)$
\end{tabular}

\begin{tabular}{|c|c|c|c|c|}
\hline \multicolumn{5}{|c|}{ Duration of practice } \\
\hline 1 to 10 years & $72(40.7)$ & $42(58.3)$ & $30(41.7)$ & $<0.001$ \\
\hline 11 to 20 years & $41(23.2)$ & $34(82.9)$ & $7(17.1)$ & \\
\hline 21 to 30 years & $44(24.9)$ & 40(90.9) & $4(9.1)$ & \\
\hline 31 and above & $20(11.3)$ & $18(90.0)$ & $2(10.0)$ & \\
\hline \multicolumn{5}{|l|}{ Income } \\
\hline 10000 to 15000 & $65(39.4)$ & $46(70.8)$ & $19(29.2)$ & 0.154 \\
\hline Above 15000 & $100(60.6)$ & $79(79.0)$ & $21(21.0)$ & \\
\hline \multicolumn{5}{|l|}{ Alcohol use } \\
\hline Yes & $17(8.4)$ & $9(52.9)$ & $8(47.1)$ & 0.031 \\
\hline No & $186(91.6)$ & $144(77.4)$ & $42(22.6)$ & \\
\hline \multicolumn{5}{|l|}{ Smoking } \\
\hline Yes & $54(26.6)$ & $28(51.9)$ & $26(48.1)$ & $<0.001$ \\
\hline No & $149(73.4)$ & $125(83.9)$ & $24(16.1)$ & \\
\hline \multicolumn{5}{|l|}{ Level of activity } \\
\hline Inactive & $66(32.5)$ & $50(75.8)$ & $16(24.2)$ & 0.217 \\
\hline Less active & $78(38.4)$ & $63(80.8)$ & $15(19.2)$ & \\
\hline Active & $59(29.1)$ & $40(67.8)$ & $19(32.2)$ & \\
\hline
\end{tabular}

The results of the adjusted and unadjusted models are presented in Table 3. In the unadjusted model, age, marital status, duration of practice, gender, smoking, and alcohol were independently associated with obesity. However, after adjusting for smoking, only age and ever used alcohol were significantly associated with obesity. The odds of obesity increased with increasing age. Individuals who do not consume alcohol had higher odds for obesity compared to those who do.

Table 3. Logistic regression showing predictors of general obesity

\begin{tabular}{|c|c|c|c|c|}
\hline Variables & Unadjusted OR (95\% CI) & p-value & Adjusted OR (95\% CI) & p-value \\
\hline \multicolumn{5}{|l|}{ Age } \\
\hline$>30$ years & $8.24(3.38-20.11)$ & $<0.001$ & $4.31(1.28-14.48)$ & 0.018 \\
\hline \multicolumn{5}{|c|}{ Less or equal to 30 years } \\
\hline \multicolumn{5}{|l|}{ Marital status } \\
\hline Ever Married & $2.83(1.47-5.46)$ & 0.002 & $1.59(0.67-3.78)$ & 0.300 \\
\hline \multicolumn{5}{|l|}{ Never married } \\
\hline \multicolumn{5}{|c|}{ Duration of practice } \\
\hline$>10$ years & $5.06(2.40-10.66)$ & $<0.001$ & $2.19(0.89-5.36)$ & 0.091 \\
\hline \multicolumn{5}{|l|}{$\leq 10$ years } \\
\hline \multicolumn{5}{|l|}{ Gender } \\
\hline Female & $4.54(1.88-10.94)$ & 0.001 & $2.26(0.71-7.17)$ & 0.165 \\
\hline Male & & & & \\
\hline
\end{tabular}




\begin{tabular}{lllll}
\hline Ever smoked & & & \\
No & $3.05(1.10-8.39)$ & 0.031 & NA & NA \\
Yes & & & & 0.001 \\
\hline Ever taken alcohol & $4.8(2.42-9.64)$ & $<0.001$ & $3.12(1.26-7.76)$ & \\
No & & & \\
Yes & & & \\
\hline
\end{tabular}

\section{Discussion}

Obesity has reached a pandemic level worldwide, and South Africa is no exception. This study sought to examine the prevalence and determinants of obesity among the supposedly health promotors and healthy lifestyle advocators, which in this case are the professional primary healthcare nurses in the Eastern Cape Province of South Africa. Surprisingly, $76 \%$ of the professional nurses are obese, with an additional $18 \%$ being overweight. This findings corroborates the widely documented high prevalence of obesity among nurses both in Africa: South Africa (Goon et al., 2013), Nigeria (Ogunjimi, Ikorok, Olayinka, 2010) Ghana (Aryee et al., 2013) and outside Africa; Scotland (Kyle, Neall \& Atherton, 2016), England (Kyle et al., 2017) and USA (Miller, Alpert \& Cross, 2008). However, the prevalence recorded in this study is higher than the prevalence documented in other studies which ranged from $16.4 \%$ to $62.2 \%$, and even in another study conducted among nurses in Vhembe district of South Africa (44.4\%) (Goon et al., 2013). The higher prevalence of obesity found among professional nurses in our study could be ascribed to the occupational work setting of working in the primary healthcare facilities, whereby professional nurses are usually in a sitting position for hours during consultation with the assistant nurses. In this setting, the primary healthcare nurse are assigned the role of consulting, diagnosis and treatment. They are often seated consulting with interrupted sessions of rendering nursing care of treatment as the need arises. The nurses in this settings often have an hour and half breaks for tea and lunch. However, in this study, the mean self-reported duration of sitting at work was $4.4(\mathrm{SD} \pm 1.5)$ hours. Sedentary lifestyle in addition to other contributing factors such as genetics, environmental factors amongst others might have contributed to the high burden of obesity.

When compared to obesity among the general population, including working population (Goon et al., 2013; Skaal \& Pengpid, 2011), the prevalence of obesity among nurses is higher than the prevalence recorded in various studies conducted among the general population in South Africa which ranged from $15 \%$ to $60.2 \%$ (Adeniyi, Longo-Mbenza \& Goon, 2015; Owolabi, Goon, Adeniyi, Adedokun \& Seekoe, 2017; Cois \& Day, 2015; Goon et al., 2013; Skaal \& Pengpid, 2011). Owolabi et al. (2015) in their study conducted among adults in the same province as the current study, with an almost similar mean age reported a lower prevalence (46\%) compared to the prevalence found among nurses in this setting. Though this study and that of Owolabi et al. (2017) was conducted in the same setting, the slight age difference in the study participants as well as the gender distribution could be the reasons for the observed difference. Also, Owolabi et al's (2017) study was conducted among the general adult population not specifically nurses. Even so, this is worrying and points at the fact that nurses, who are supposed to be health promotion models and are knowledgeable about the health implications of overweight and obesity appears to be more obese than the general population.

Although, the profession is dominated by females, with a usually higher prevalence of obesity, even so, these findings suggest nurses might not be practising the healthy lifestyle they advocate for. In other words, they are not living up to what they preach to patients about weight health matters. This have significant health implications as patients and the entire community might use the weight of their health providers as a form of excuse and will hardly accept counsel from such health professionals. In addition, overweight and obese nurses have been documented to have lesser confidence in health educating patients on the need for weight control (Kyle, Neall \& Atherton, 2016). Therefore, there is a possibility of shying away from such teachings, which portends poor health advocacy communication from the sender and the receiver, thus invariably accelerating the obesity burden. Likewise, the high burden of obesity among nurses, one of the key stakeholders in healthcare could also endanger this workforce. The high burden of obesity among them would predispose them to several other disease conditions such as hypertension and diabetes, which are leading contributing factors to morbidity and mortality (WHO, 2016; WHO, 2014). There is a need for a qualitative study aimed at exploring the views, perspective and reasons of the nurses for not integrating their lifestyle recommendation into their daily routines. As such, that will assist in identifying the needed intervention for this important group. Even though we do not have a data on nursing curriculum in this settings, as well as the nutritional knowledge of these nurses, this could have also influenced the observed prevalence in this study. 
Of all the demographic and behavioural factors, gender, marital status, age, duration of practice, alcohol use and smoking were found to be associated with obesity among the study participants. However, only age and non-alcohol use were the significant predictors of obesity. Female nurses were found to be more obese than the male ones. Generally in South Africa, females have been shown to be more obese than males (Cois \& Day, 2015). This is similar to the findings of Aryee et al. (2013) among nurses in Ghana. Studies among the general population have also documented a higher prevalence of obesity among females ${ }^{21,22}$ compared to males. Some studies among the general population outside Africa, however, reported a higher prevalence of obesity among males (Cai, Han, Qi, Li, Zhang, \& Liu, 2014; Naveneelan \& Janz, 2014). Although Jakicic, Otto and Loss (2005) and Chukwuonye et al (2013) ascribed the higher prevalence of obesity among females to inadequate engagement in physical activity, our study found no significant relationship between physical activity and obesity. In addition to physical inactivity, several other factors contribute to the obesity epidemic. A plausible reason for the higher prevalence among the female nurses could be as a result of the physiological changes which usually take place during the reproductive years of women (Gunderson, 2009). This could also be responsible for the higher prevalence found among the married participants as the study population are largely females. Notwithstanding, this does not connote a causal link between marriage and obesity. Several other factors in addition to the listed factors; such as genetics, environmental influence could contribute to the obesity burden.

Another important factor associated with obesity was ageing. Obesity was found to be higher among the older participants. This is similar to the finding among Ghanaian nurses (Aryee et al., 2013). This is however contrary to the findings among the general populace in Uganda (Kirunda, Fadnes, Wamani, Broeck, Tylleskar, 2015). Older adults might engage in lesser physical activity and this might be the reason behind the higher prevalence of obesity among the older ones. Also, the older nurses are more experienced and may be more involved in the consultations, long sitting hours, while the younger ones carry out other procedures and render care to the patients. This also applies to those with longer duration of practice as they constitute the higher age group, although we cannot categorically say that this is the case among our study participants.

Finally, nurses who do not consume alcohol and do not smoke were found to have a higher prevalence of obesity. These findings needs to be interpreted with caution. The higher prevalence of obesity seen among those who do not smoke is consistent with other studies (Mackay, Gray, Pell, 2013; Gallus, Lugo, Murisic, Bosetti, Boffetta, Vecchia 2015) which documented inadvertent weight loss among smokers. Also, there is a complex inter-relation between obesity and alcohol use. While some authors documented that alcohol consumption leads to weight gain (Shelton \& Knott, 2014; Traversy \& Chaput, 2015) following appetite stimulation, one study reported no definite relationship between alcohol use and obesity (Cready \& Kyle, 2016). Nonetheless, the overall effect of smoking and harmful alcohol use is detrimental to health and should not be encouraged. In all, the significant role played by socio-economic status, ethnicity, food marketing and physical environment on these modifiable factors cannot be overlooked, which often makes the prevention of obesity a challenging task and might have also contributed to the high and growing burden of overweight and obesity

\section{Strengths and Limitations}

This is the first study on overweight and obesity among professional primary health care nurses in South Africa, to the best of our knowledge. Such information highlights the the burden of obesity among professional primary health nurses who are health promotors in the rural settings of the province. However, given that the study was conducted in a province, our results cannot be generalized to the entire nurses in South Africa. Also, the reliance on self-reported health-related behaviour data, the cross-sectional approach used, small sample size and the sampling the clinics conveniently limits the study, even though the districts were randomly selected.

\section{Conclusion}

This study shows an alarmingly high prevalence of overweight and obesity among professional primary healthcare nurses in the Eastern Cape Province of South Africa. This indicates that the primary healthcare nurses in this settings might not be practising the health promotion behaviours they advocate for and this might limit their ability to act as positive health role models for their patients/clients. There is an urgent need for the district health managers and the provincial policy makers to promptly implement measures to curb this growing menace.

\section{Availability of Data}

Data from this study will be made available on request.

\section{Acknowledgements}

The authors are grateful to the Health and Welfare Sector Education and Training Authority, South Africa, for the study grant given to SM for the implementation of the project. We also appreciate the management and nursing staff of the health facilities for their support towards the successful implementation of the project. 


\section{Competing Interests Statement}

The authors declare that there are no competing or potential conflicts of interest.

\section{References}

Adeniyi, O. V., Longo-Mbenza, B., \& Ter Goon, D. (2015). Female sex, poverty and globalization as determinants of obesity among rural South African type 2 diabetics: a cross-sectional study. BMC Public Health, 15(1). https://doi.org/10.1186/s12889-015-1622-8

Aryee, P., Helegbe, G., Baah, B., Sarfo-Asante, R., \& Quist-Therson, R. (2014). Prevalence and Risk Factors for Overweight and Obesity among Nurses in the Tamale Metropolis of Ghana. Journal of Medical and Biomedical Sciences, 2(4), 13. https://doi.org/10.4314/jmbs.v2i4.3

Bogossian, F. E., Hepworth, J., Leong, G. M., Flaws, D. F., Gibbons, K. S., Benefer, C. A., \& Turner, C. T. (2012). A cross-sectional analysis of patterns of obesity in a cohort of working nurses and midwives in Australia, New Zealand, and the United Kingdom. International Journal of Nursing Studies, 49(6), 727-738. https://doi.org/10.1016/j.ijnurstu.2012.01.003

Bonita, R., Winkelmann, R., Douglas, K. A., \& de Courten, M. (2003). The WHO Stepwise Approach to Surveillance (Steps) of Non-Communicable Disease Risk Factors. Global Behavioral Risk Factor Surveillance, 9-22. https://doi.org/10.1007/978-1-4615-0071-1_3

Cai, L., Han, X., Qi, Z., Li, Z., Zhang, Y., Wang, P., \& Liu, A. (2014). Prevalence of Overweight and Obesity and Weight Loss Practice among Beijing Adults, 2011. PLoS ONE, 9(9), e98744. https://doi.org/10.1371/journal.pone.0098744

Chukwuonye, I. I., John, Ohagwu, Ejiji, Imoh, Chuku, ... Oviasu. (2013). Prevalence of overweight and obesity in adult Nigerians \&ndash; a systematic review. Diabetes, Metabolic Syndrome and Obesity: Targets and Therapy, 43. https://doi.org/10.2147/DMSO.S38626

Cois, A., \& Day, C. (2015). Obesity trends and risk factors in the South African adult population. BMC Obesity, 2(1). https://doi.org/10.1186/s40608-015-0072-2

Finucane, M. M., Stevens, G. A., Cowan, M. J., Danaei, G., Lin, J. K., Paciorek, C. J., ... Ezzati, M. (2011). National, regional, and global trends in body-mass index since 1980: systematic analysis of health examination surveys and epidemiological studies with 960 country-years and $9 \bullet 1$ million participants. The Lancet, 377(9765), 557-567. https://doi.org/10.1016/S0140-6736(10)62037-5

Gallus, S., Lugo, A., Murisic, B., Bosetti, C., Boffetta, P., \& La Vecchia, C. (2014). Overweight and obesity in 16 $\begin{array}{lllll}\text { European countries. European Journal of Nutrition, 54(5), 679-689. } & \text {. }\end{array}$ https://doi.org/10.1007/s00394-014-0746-4

Goon, D., Maputle, M., Olukoga, A., Lebese, R., Khoza, L., \& Ayanwu, F. (2013). Overweight, obesity and underweight in nurses in Vhembe and Capricorn districts, Limpopo. South African Journal of Clinical Nutrition, 26(3), 147-149. https://doi.org/10.1080/16070658.2013.11734459

Gunderson, E. P. (2009). Childbearing and Obesity in Women: Weight Before, During, and After Pregnancy. Obstetrics and Gynecology Clinics of North America, 36(2), 317-332. https://doi.org/10.1016/j.ogc.2009.04.001

Jakicic, J. M., \& Otto, A. D. (2005). Physical activity considerations for the treatment and prevention of obesity. The American Journal of Clinical Nutrition, 82(1), 226S-229S. https://doi.org/10.1093/ajcn/82.1.226S

Khamisa, N., Peltzer, K., \& Oldenburg, B. (2013). Burnout in Relation to Specific Contributing Factors and Health Outcomes among Nurses: A Systematic Review. International Journal of Environmental Research and Public Health, 10(6), 2214-2240. https://doi.org/10.3390/ijerph10062214

Kirunda, B. E., Fadnes, L. T., Wamani, H., Van den Broeck, J., \& Tylleskär, T. (2015). Population-based survey of overweight and obesity and the associated factors in peri-urban and rural Eastern Uganda. BMC Public Health, 15(1). https://doi.org/10.1186/s12889-015-2506-7

Kyle, R. G., Neall, R. A., \& Atherton, I. M. (2016). Prevalence of overweight and obesity among nurses in Scotland: A cross-sectional study using the Scottish Health Survey. International Journal of Nursing Studies, 53, 126-133. https://doi.org/10.1016/j.ijnurstu.2015.10.015

Kyle, R. G., Wills, J., Mahoney, C., Hoyle, L., Kelly, M., \& Atherton, I. M. (2017). Obesity prevalence among healthcare professionals in England: a cross-sectional study using the Health Survey for England. BMJ Open, 7(12), e018498. https://doi.org/10.1136/bmjopen-2017-018498 
Mackay, D. F., Gray, L., \& Pell, J. P. (2013). Impact of smoking and smoking cessation on overweight and obesity: Scotland-wide, cross-sectional study on 40,036 participants. BMC Public Health, 13(1). https://doi.org/10.1186/1471-2458-13-348

Miller, S. K., Alpert, P. T., \& Cross, C. L. (2008). Overweight and obesity in nurses, advanced practice nurses, and nurse educators. Journal of the American Academy of Nurse Practitioners, 20(5), 259-265. https://doi.org/10.1111/j.1745-7599.2008.00319.x

Navaneelan, T., \& Janz, T. (2014). Adjusting the scales: obesity in the Canadian population after correcting for respondent bias. Statistics Canada. https://doi.org/10.2307/2733685

Nnyepi, M. S., Gwisai, N., Lekgoa, M., \& Seru, T. (2015). Evidence of nutrition transition in Southern Africa. Proceedings of the Nutrition Society, 74(04), 478-486. https://doi.org/10.1017/S0029665115000051

Ogunjimi, L. O., Ikorok, M. M., \& Olayinka, O. (2010). Prevalence of obesity among Nigeria nurses: The Akwa Ibom state experience. International NGO Journal, 5(2), 045-049.

Owolabi, E. O., Ter Goon, D., \& Adeniyi, O. V. (2017). Central obesity and normal-weight central obesity among adults attending healthcare facilities in Buffalo City Metropolitan Municipality, South Africa: a cross-sectional study. Journal of Health, Population and Nutrition, 36(1). https://doi.org/10.1186/s41043-017-0133-x

Phiri, L. P., Draper, C. E., Lambert, E. V., \& Kolbe-Alexander, T. L. (2014). Nurses' lifestyle behaviours, health priorities and barriers to living a healthy lifestyle: a qualitative descriptive study. BMC Nursing, 13(1). https://doi.org/10.1186/s12912-014-0038-6

Shelton, N. J., \& Knott, C. S. (2014). Association Between Alcohol Calorie Intake and Overweight and Obesity in English Adults. American Journal of Public Health, 104(4), 629-631. https://doi.org/10.2105/AJPH.2013.301643

Skaal, L., \& Pengpid, S. (2011). Obesity and health problems among South African healthcare workers: do healthcare workers take care of themselves? South African Family Practice, 53(6), 563-567. https://doi.org/10.1080/20786204.2011.10874153

South African Nursing Council. Competencies for primary care nurse specialist. Retrieved 7th July, 2017 from http://www.sanc.co.za/pdf/Competencies/SANC\%20Competencies-Primary\%20Care\%20Nurse\%20Special ist\%202014-05.pdf

Statistics South Africa. (2011). South African Statistics, South Africa. 2011; 1-190. http://www.statssa.gov.za/publications/SAStatistics/SAStatistics2011.pdf

Steyn, N., Mann, J., Bennett, P., Temple, N., Zimmet, P., Tuomilehto, J., ... Louheranta, A. (2004). Diet, nutrition and the prevention of type 2 diabetes. Public Health Nutrition, 7(1a). https://doi.org/10.1079/PHN2003586

Traversy, G., \& Chaput, J.-P. (2015). Alcohol Consumption and Obesity: An Update. Current Obesity Reports, 4(1), 122-130. https://doi.org/10.1007/s13679-014-0129-4

World Health Organisation [WHO]. (2016). Obesity and overweight factsheet March 2011. Retrieved 7th June, 2017 from http://www.who.int/mediacentre/factsheets/fs311/en/

World Health Organisation [WHO]. (2011). Waist Circumference and Waist-Hip Ratio Report of a WHO Expert Consultation. Geneva. 2011.

World Health Organization [WHO]. (2014). Non-communicable disease prevention and control. World Health Organization, South Africa Country Office, Johannesburg.

\section{Copyrights}

Copyright for this article is retained by the author(s), with first publication rights granted to the journal.

This is an open-access article distributed under the terms and conditions of the Creative Commons Attribution license (http://creativecommons.org/licenses/by/4.0/). 